\title{
Epicardial adipose tissue thickness as a potential predictor of gestational diabetes mellitus: a prospective cohort study
}

\author{
Jing Liu', Guang Song ${ }^{2}$, Tao Meng ${ }^{1 *}$ and Ge Zhao ${ }^{1}$
}

\begin{abstract}
Background: Gestational diabetes mellitus (GDM) is the most common metabolic disorder that can occur during pregnancy and is associated with a long-term risk of both maternal and neonatal comorbidities. This study aimed to investigate the association between echocardiographic epicardial adipose tissue (EAT) and the risk for GDM during the early second trimester of pregnancy.

Method: We recruited all singleton pregnancies between January 2014 and December 2018 at 16 weeks + 0 days to 19 weeks +6 days. We then used generalized linear models to calculate odds ratios (ORs) and $95 \%$ confidence intervals (Cls) for EAT as a potential predictor for GDM. Receiver-operating-characteristic (ROC) analysis was then conducted to investigate the discriminative capacity of any individual maternal factor for the prediction of GDM.

Results: In total, our study involved 314 pregnant women with GDM and 1832 pregnant women without GDM. Multivariate regression analysis revealed that EAT thickness ( $\mathrm{OR}=2.87 ; 95 \% \mathrm{Cl}: 2.49-3.31)$ was significantly associated with the presence of GDM $(P<0.001)$. Furthermore, EAT thickness was also significantly associated with a range of adverse outcomes in the GDM group, including large size for gestational age, neonatal hypoglycemia, admission to the neonatal intensive care unit, preterm delivery, and hyperbilirubinemia $(P<0.001)$. ROC analysis revealed that the area under the curve was 0.790 (95\% Cl: 0.768-0.812). When the cutoff value for EAT thickness was set to $5.49 \mathrm{~mm}$, the sensitivity was $95.2 \%$ and the specificity was $50.5 \%$.

Conclusions: Echocardiographic EAT thickness is positively and significantly associated with both the risk of GDM and adverse outcomes related to GDM. Echocardiographic EAT has the potential to predict GDM prior to actual clinical diagnosis.
\end{abstract}

Keywords: Gestational diabetes mellitus, Epicardial adipose tissue, Prediction, Echocardiography

\section{Background}

Gestational diabetes mellitus (GDM), the most common metabolic disorder of pregnancy, is a condition in which carbohydrate intolerance develops during pregnancy. The offspring of women with GDM are at an increased risk of macrosomia, neonatal hypoglycemia, and hyperbilirubinemia.

\footnotetext{
* Correspondence: mengtao201011@163.com

${ }^{1}$ Department of Obstetrics, The First Affiliated Hospital of China Medical University, No. 155 Nanjing North Street, Heping District, Shenyang 110001, Liaoning Province, China

Full list of author information is available at the end of the article
}

The prevalence of GDM varies from 1 to $20 \%$, and is rising worldwide, parallel to the increased prevalence of obesity and type 2 diabetes mellitus (T2DM) [1]. As reported previously, the prevalence of GDM in a population of pregnant women usually reflects the prevalence of T2DM in that particular population [2].

It is important to predict GDM early in pregnancy to enable early interventions that could prevent GDM and reduce adverse outcomes. Currently, there are no established guidelines for the prediction of GDM and no

(c) The Author(s). 2020 Open Access This article is licensed under a Creative Commons Attribution 4.0 International License, which permits use, sharing, adaptation, distribution and reproduction in any medium or format, as long as you give appropriate credit to the original author(s) and the source, provide a link to the Creative Commons licence, and indicate if changes were made. The images or other third party material in this article are included in the article's Creative Commons licence, unless indicated otherwise in a credit line to the material. If material is not included in the article's Creative Commons licence and your intended use is not permitted by statutory regulation or exceeds the permitted use, you will need to obtain permission directly from the copyright holder. To view a copy of this licence, visit http://creativecommons.org/licenses/by/4.0/ The Creative Commons Public Domain Dedication waiver (http://creativecommons.org/publicdomain/zero/1.0/) applies to the data made available in this article, unless otherwise stated in a credit line to the data. 
effective modalities for the prevention of its future development prior to actual diagnosis. According to existing literature, excessive body weight/obesity is the main risk factor for GDM [3]. Clinicians usually use body mass index (BMI) to assess maternal obesity during pregnancy. However, previous studies found that BMI may not be a good predictor for GDM around the first trimester $[4,5]$, due to its inability to reflect the accumulation and mass of the visceral adipose tissue (VAT) [6]. Recently, a promising echocardiographic parameter, epicardial adipose tissue (EAT), has emerged that could complement the use of BMI to assess risk for GDM. EAT is closely related to metabolic syndrome and diabetes $[7,8]$, and is an independent predictor of visceral adiposity, as measured by echocardiography [9]. This study aimed to investigate the association between the EAT thickness and GDM, and assess the efficacy of EAT thickness as a potential predictor for GDM at 16 weeks + 0 days to 19 weeks +6 days before the diagnosis of GDM.

\section{Methods}

\section{Study design, setting, and population}

This prospective cohort study was conducted at the First Affiliated Hospital of China Medical University. All participants were admitted to our obstetric clinic between January 2014 and December 2018. All participants provided written informed consent and the study protocol was approved by the Medical Ethics Review Board of China Medical University (Shenyang, Liaoning, China).

\section{Criteria}

Participants were eligible if they: (1) had a singleton pregnancy; (2) had their first pregnancy visit before 19 weeks +6 days (gestational age was determined by ultrasound within 3 months of pregnancy confirmation); (3) signed the informed consent form and provided a complete medical history. Participants were not eligible if they had a history of diabetes (including GDM in previous pregnancies), hypertension, or cardiovascular diseases.

\section{Data collection between 16 weeks +0 days and 19 weeks +6 days}

A range of anthropometric parameters were measured for each participant, including weight, height, heart rate, systolic blood pressure, and diastolic blood pressure; we also calculated the BMI [10]. At each visit, we also recorded the family history of diabetes as a parent or sibling may have been diagnosed as having diabetes in the interval since the previous visit [11].

A peripheral blood sample was collected from each participant before 19 weeks +6 days; samples were collected in a vacutainer collection tube. We used the blood samples to determine the lipid profile of each participant, including triglyceride, total cholesterol, high- density lipoprotein cholesterol (HDL-C), and lowdensity lipoprotein cholesterol (LDL-C); these parameters were determined with an auto-analyzer (AU1000; Olympus, Tokyo, Japan).

Maternal echocardiography was also performed between 16 weeks +0 days and 19 weeks +6 days. All images were obtained using a Philips iE33 system (Philips Medical Systems, Bothell, WA, USA) with a $1.5 / 5 \mathrm{MHz}$ phased array probe. Maternal EAT thickness was measured by echocardiography in the parasternal long-axis view at the level of the fold of Rindfleisch, between the free wall of the right ventricle and the anterior surface of the ascending aorta [12].

\section{Data collection between 24 weeks +0 days and 28 weeks +0 days}

A two-hour 75-g oral glucose tolerance test (OGTT) was used to test for GDM; these tests were carried out after an overnight fast. The following morning, we tested the fasting plasma glucose concentration and then asked the participant to drink $250-300 \mathrm{~mL}$ of water containing $75 \mathrm{~g}$ of sugar. We then determined plasma glucose levels 1 hour and 2 hours later [13].

GDM was diagnosed according to the International Association of Diabetes and Pregnancy Study Groups [13]. A diagnosis of GDM was made when one or more of the test parameters equaled or exceeded the following cut points: fasting $92 \mathrm{mg} / \mathrm{dL}(5.1 \mathrm{mmol} / \mathrm{L}), 1-\mathrm{h} 180 \mathrm{mg} /$ dL $(10.0 \mathrm{mmol} / \mathrm{L})$, or 2 -h $153 \mathrm{mg} / \mathrm{dL}(8.5 \mathrm{mmol} / \mathrm{L})$.

\section{Follow-up of neonatal outcomes in GDM patients}

Adverse neonatal outcomes were recorded after delivery, including large size for gestational age, neonatal hypoglycemia, admission to the neonatal intensive care unit (NICU), preterm delivery, and hyperbilirubinemia. Large size for gestational age was defined as the birth weight at or above the gestational age-specific 90th percentile [3]. Neonatal hypoglycemia was defined as a blood glucose concentration $<47 \mathrm{mg} / \mathrm{dL} \quad(<2.6 \mathrm{mmol} / \mathrm{L}) \quad[14]$. Preterm was defined as delivery before 37 weeks of pregnancy [15]. Hyperbilirubinemia was defined as a bilirubin level that, at any time after birth, exceeded the hour-specific phototherapy treatment threshold recommended in the American Academy of Pediatrics' clinical practice guideline on the management of neonatal hyperbilirubinemia [16].

\section{Statistical analysis}

Statistical analysis was performed using STATA version 14.0 software. Continuous parameters were expressed as the mean \pm standard deviation. Non-normally distributed parameters were expressed as the median. Differences of normally distributed continuous parameters between groups were analyzed using the independent-samples $t$ test. Differences of non-normally distributed parameters 
between groups were analyzed using the Mann-Whitney $\mathrm{U}$ test. Differences of categorial parameters between groups were analyzed using Pearson's chi-squared test. Odds ratio (OR) and 95\% confidence intervals (CIs) of individual maternal factors, as potential predictors for GDM, were calculated using generalized linear models. Receiver-operating-characteristic (ROC) analysis was conducted to assess the discriminative capacity of any individual maternal factor for the prediction of GDM. A two-tailed $P<0.05$ was used to define statistical significance.

\section{Results}

\section{Baseline maternal characteristics}

A total of 2146 mothers met our eligibility criteria and were included in the main analysis; 314 of these mothers had GDM and 1832 did not (Fig. 1). Table 1 shows the baseline clinical characteristics of the participants as compared between the GDM and control groups. There were significant differences between the two groups with respect to maternal age, BMI, lipid profiles (triglyceride, total cholesterol, and HDL-C), and EAT thickness $(P=$ $0.018, P=0.026, P=0.018, P=0.015, P=0.007, P<0.001$, respectively). Overall, 47, 102, 113, and 52 participants received maternal echocardiography at 16-17, 17-18, 18-19, and 19-20 weeks of gestation in the GDM group. In the control group, 310, 628, 611, and 283 participants received maternal echocardiography at 16-17, 17-18, 18-19, and 19-20 weeks of gestation.

\section{Regression analysis for the presence of GDM}

The results of all regression analyses are summarized in Table 2. Univariate regression analysis revealed that maternal age $(\mathrm{OR}=1.05,95 \% \mathrm{CI}: 1.01-1.09)$, BMI $(\mathrm{OR}=$ 1.05, 95\% CI: 1.01-1.09), triglyceride $(\mathrm{OR}=1.23,95 \% \mathrm{CI}$ : 1.04-1.46), total cholesterol (OR $=1.21,95 \% \mathrm{CI}: 1.04-$ 1.41), HDL-C (OR $=0.42,95 \% \mathrm{CI}: 0.22-0.79)$, and EAT thickness $\quad(\mathrm{OR}=2.92, \quad 95 \% \quad \mathrm{CI}: \quad 2.54-3.36) \quad$ were

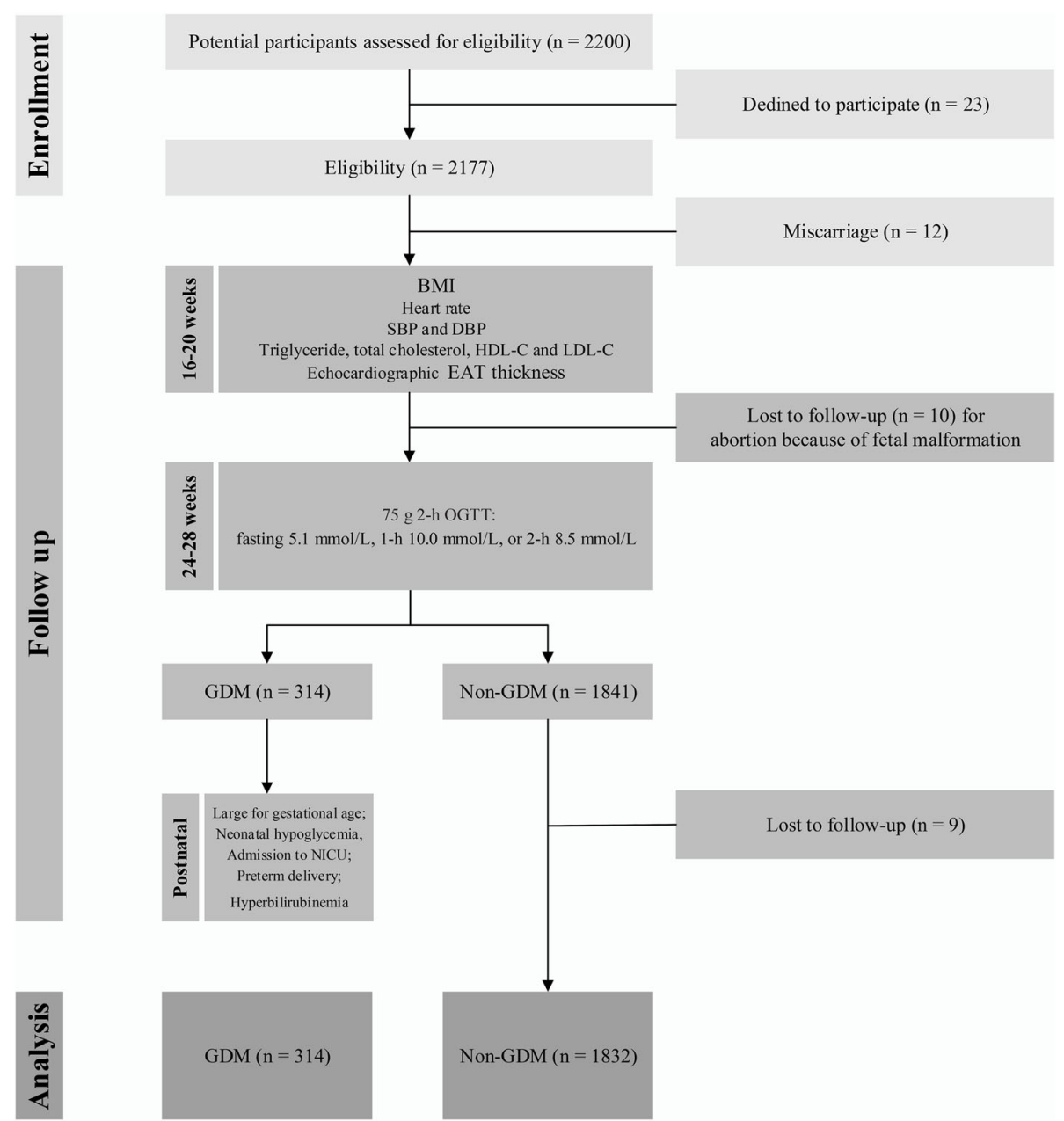

Fig. 1 Study flow diagram. BMI, body mass index; DBP, diastolic blood pressure; EAT, epicardial adipose tissue; GDM, gestational diabetes mellitus; HDL-C, high-density lipoprotein cholesterol; LDL-C, low-density lipoprotein cholesterol; NICU, neonatal intensive care unit; OGTT, oral glucose tolerance test; SBP, systolic blood pressure 
Table 1 Baseline characteristics of participants in GDM and control groups

\begin{tabular}{|c|c|c|c|}
\hline & GDM $(n=314)$ & Control $(n=1832)$ & $P$ \\
\hline Maternal age (years) & $32.10 \pm 3.02$ & $31.66 \pm 3.01$ & 0.018 \\
\hline Height (m) & $1.63 \pm 0.04$ & $1.63 \pm 0.05$ & 0.106 \\
\hline Weight (kg) & $60.42 \pm 7.25$ & $59.76 \pm 7.11$ & 0.128 \\
\hline BMI $\left(\mathrm{kg} / \mathrm{m}^{2}\right)$ & $22.86 \pm 3.07$ & $22.46 \pm 2.87$ & 0.026 \\
\hline Gravida $^{a}$ & 1 & 1 & 0.504 \\
\hline Parity & 0 & 0 & 0.734 \\
\hline Family history of diabetes & $21(7 \%)$ & $94(5 \%)$ & 0.258 \\
\hline Heart rate (beats/minute) & $74.26 \pm 8.04$ & $73.36 \pm 9.11$ & 0.100 \\
\hline SBP $(\mathrm{mmHg})$ & $115.71 \pm 5.71$ & $115.20 \pm 6.33$ & 0.184 \\
\hline $\mathrm{DBP}(\mathrm{mmHg})$ & $73.05 \pm 6.00$ & $72.87 \pm 5.45$ & 0.585 \\
\hline \multicolumn{4}{|l|}{ Triglyceride } \\
\hline $\mathrm{mg} / \mathrm{dL}$ & $233.68 \pm 61.59$ & $224.81 \pm 61.61$ & 0.018 \\
\hline $\mathrm{mmol} / \mathrm{L}$ & $2.65 \pm 0.70$ & $2.55 \pm 0.70$ & 0.018 \\
\hline \multicolumn{4}{|l|}{ Total cholesterol } \\
\hline $\mathrm{mg} / \mathrm{dL}$ & $240.92 \pm 29.22$ & $236.45 \pm 30.19$ & 0.015 \\
\hline $\mathrm{mmol} / \mathrm{L}$ & $6.26 \pm 0.76$ & $6.15 \pm 0.78$ & 0.015 \\
\hline \multicolumn{4}{|l|}{$\mathrm{HDL}-\mathrm{C}$} \\
\hline $\mathrm{mg} / \mathrm{dL}$ & $68.10 \pm 9.01$ & $69.31 \pm 6.99$ & 0.007 \\
\hline $\mathrm{mmol} / \mathrm{L}$ & $1.76 \pm 0.23$ & $1.79 \pm 0.18$ & 0.007 \\
\hline \multicolumn{4}{|l|}{ LDL-C } \\
\hline $\mathrm{mg} / \mathrm{dL}$ & $129.37 \pm 22.12$ & $130.94 \pm 21.82$ & 0.239 \\
\hline $\mathrm{mmol} / \mathrm{L}$ & $3.36 \pm 0.58$ & $3.40 \pm 0.57$ & 0.239 \\
\hline EAT thickness (mm) & $6.57 \pm 0.79$ & $5.49 \pm 1.05$ & $<0.001$ \\
\hline
\end{tabular}

$B M I$ Body mass index, DBP Diastolic blood pressure, EAT Epicardial adipose tissue, GDM Gestational diabetes mellitus, HDL-C High-density lipoprotein cholesterol, LDL-C Low-density lipoprotein cholesterol, SBP Systolic blood pressure. All the parameters (except for gravida, parity, and family history) were expressed as the mean \pm standard deviation. Gravida and parity were expressed as the median

${ }^{a}$ Gravida describes the total number of confirmed pregnancies that a woman has had, regardless of the outcome significantly associated with the presence of GDM. Multivariate regression analysis further revealed that EAT thickness $(\mathrm{OR}=2.87,95 \% \mathrm{CI}: 2.49-3.31)$ were significantly associated with the presence of GDM $(P<0.001)$.

\section{ROC analysis}

ROC analysis was performed to verify whether EAT thickness could predict GDM. The ROC curve is shown in Fig. 2. The area under the curve was 0.790 (95\% CI: $0.768-0.812$ ). When the cutoff value was set to $5.49 \mathrm{~mm}$, the sensitivity was $95.2 \%$ and the specificity was $50.5 \%$.

\section{The association of EAT thickness with adverse outcomes in the GDM group}

Table 3 shows that the EAT was significantly higher in patients with adverse outcomes when compared with the patients without adverse outcomes in the GDM group $(P<0.001)$. Regression analysis further revealed that EAT thickness was a significant risk factor for large size for gestational age ( $\mathrm{OR}=3.47,95 \% \mathrm{CI}$ : $2.29-5.26)$, neonatal hypoglycemia $(\mathrm{OR}=3.10,95 \% \mathrm{CI}: 1.78-5.37)$, admission to NICU $(\mathrm{OR}=4.38,95 \%$ CI: 2.81-6.84), preterm delivery $(\mathrm{OR}=4.67,95 \% \mathrm{CI}: 2.84-7.68)$, and hyperbilirubinemia (OR $=4.04,95 \% \mathrm{CI}: 2.24-7.28)$ (all $P<0.001)$. Overall, EAT thickness was a significant risk factor for adverse outcomes in GDM patients $(\mathrm{OR}=$ 8.28, 95\% CI: 5.10-13.43, $P<0.001)$.

\section{Discussion}

Possessing the ability to predict GDM as early as possible is a very important goal and has been pursued by researchers over many years as this could allow for early lifestyle changes and/or nutritional interventions to prevent GDM. Unfortunately, pregnancy is a complex and dynamic process, involving profound changes in energy and nutrient metabolism to sustain fetal development and growth, and to meet the requirements of labor and lactation. To date, although many risk factors for GDM have been identified (e.g., maternal age, obesity, and lipid

Table 2 Results of univariate and multivariate regression analysis for the presence of GDM

\begin{tabular}{|c|c|c|c|c|}
\hline & \multicolumn{2}{|c|}{ Univariate regression } & \multicolumn{2}{|c|}{ Multivariate regression } \\
\hline & OR $(95 \% \mathrm{Cl})$ & P & OR $(95 \% \mathrm{Cl})$ & P \\
\hline Maternal age (years) & $1.05(1.01-1.09)$ & 0.018 & $1.03(0.98-1.07)$ & 0.223 \\
\hline BMI $\left(\mathrm{kg} / \mathrm{m}^{2}\right)$ & $1.05(1.01-1.09)$ & 0.026 & $1.03(0.98-1.08)$ & 0.230 \\
\hline Triglyceride (mg/dL) & $1.23(1.04-1.46)$ & 0.018 & $1.16(0.96-1.40)$ & 0.130 \\
\hline Total cholesterol (mg/dL) & $1.21(1.04-1.41)$ & 0.015 & $1.06(0.90-1.26)$ & 0.483 \\
\hline $\mathrm{HDL}-\mathrm{C}(\mathrm{mg} / \mathrm{dL})$ & $0.42(0.22-0.79)$ & 0.007 & $0.42(0.21-0.83)$ & 0.011 \\
\hline EAT thickness (mm) & $2.92(2.54-3.36)$ & $<0.001$ & $2.87(2.49-3.31)$ & $<0.001$ \\
\hline
\end{tabular}

$B M I$ Body mass index, $\mathrm{Cl}$ Confidence interval, EAT Epicardial adipose tissue, GDM Gestational diabetes mellitus, HDL-C High-density lipoprotein cholesterol, $O R$ Odds ratio 


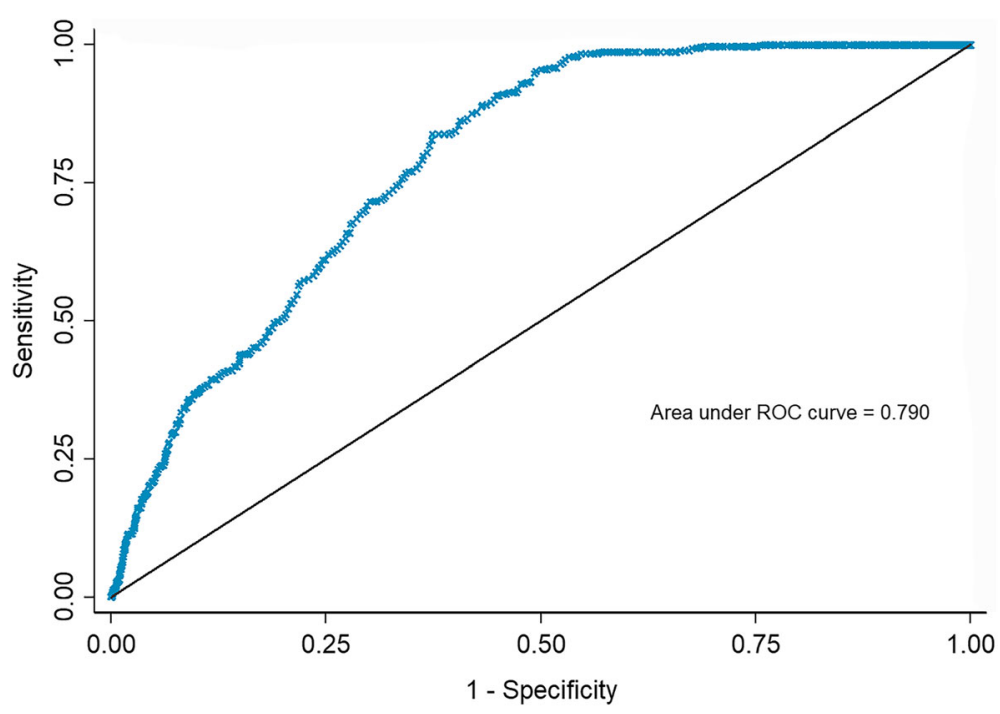

Fig. 2 Receiver operating characteristic (ROC) curves for EAT thickness for the prediction of GDM. EAT, epicardial adipose tissue; GDM, gestational diabetes mellitus

profiles), no validated tool exists to predict the risk of GDM.

Clinicians usually use BMI, VAT, and subcutaneous adipose tissue (SAT), to assess obesity when trying to predict GDM. However, SAT is not a good predictor for GDM during the first trimester $[17,18]$; neither is BMI $[4,5,19]$. Over recent years, several studies have revealed that VAT could be a good predictor for GDM in the first and second trimesters $[18,19]$. It remains unclear whether EAT, as a special type of VAT, exerts a similar performance when screening for GDM.

EAT has a range of functions, including lipogenic capacity [20]. A number of researchers have focused on the adverse effects of EAT and confirmed this parameter as a marker of diabetic risk [8]. A previous study also revealed that EAT thickness was significantly higher in women with a history of GDM than controls [21]. Subsequently, two cross-sectional studies found a difference in EAT thickness when comparing between GDM and control groups during the second trimester [22, 23]. In these two previous studies, EAT thickness was measured at 24-28 gestational weeks (GW) at the time of GDM diagnosis. However, this is not the appropriate time for clinicians to make early interventions to prevent GDM. Therefore, we designed this study to identify whether EAT can act as a potential predictor during the early second trimester.

EAT thickness can be measured by echocardiography during pregnancy. This measurement has been proven to be both accurate and reproducible [12]. Abnormal

Table 3 Association of EAT thickness with adverse outcomes in the GDM group ( $n=314)$

\begin{tabular}{|c|c|c|c|c|c|c|}
\hline & $\begin{array}{l}\text { Cases with adverse } \\
\text { outcomes }\end{array}$ & $\begin{array}{l}\text { With adverse } \\
\text { outcomes }\end{array}$ & $\begin{array}{l}\text { Without adverse } \\
\text { outcomes }\end{array}$ & $P^{*}$ & OR $(95 \% \mathrm{Cl})$ & $P^{\#}$ \\
\hline Total & 91 (29\%) & $7.29 \pm 0.66$ & $6.27 \pm 0.64$ & $\begin{array}{l}< \\
0.001\end{array}$ & $\begin{array}{l}8.28(5.10- \\
13.43)\end{array}$ & $\begin{array}{l}< \\
0.001\end{array}$ \\
\hline $\begin{array}{l}\text { Large size for gestational } \\
\text { age }\end{array}$ & $54(17 \%)$ & $7.19 \pm 0.80$ & $6.43 \pm 0.73$ & $\begin{array}{l}< \\
0.001\end{array}$ & $3.47(2.29-5.26)$ & $\begin{array}{l}< \\
0.001\end{array}$ \\
\hline Neonatal hypoglycemia & $23(7 \%)$ & $7.25 \pm 0.73$ & $6.51 \pm 0.77$ & $\begin{array}{l}< \\
0.001\end{array}$ & $3.10(1.78-5.37)$ & $\begin{array}{l}< \\
0.001\end{array}$ \\
\hline Admission to NICU & 54 (17\%) & $7.28 \pm 0.65$ & $6.41 \pm 0.74$ & $\begin{array}{l}< \\
0.001\end{array}$ & $4.38(2.81-6.84)$ & $\begin{array}{l}< \\
0.001\end{array}$ \\
\hline Preterm delivery & $41(13 \%)$ & $7.36 \pm 0.53$ & $6.44 \pm 0.76$ & $\begin{array}{l}< \\
0.001\end{array}$ & $4.67(2.84-7.68)$ & $\begin{array}{l}< \\
0.001\end{array}$ \\
\hline Hyperbilirubinemia & $23(7 \%)$ & $7.39 \pm 0.64$ & $6.50 \pm 0.77$ & $\begin{array}{l}< \\
0.001\end{array}$ & $4.04(2.24-7.28)$ & $\begin{array}{l}< \\
0.001\end{array}$ \\
\hline
\end{tabular}

Cl Confidence interval, EAT Epicardial adipose tissue, GDM Gestational diabetes mellitus, NICU Neonatal intensive care unit, OR odds ratio $P^{*}: P$-value of independent-samples $t$-test

$P^{\#}: P$-value of univariate regression between epicardial adipose tissue thickness and adverse outcomes using generalized linear models 
levels of blood sugar in GDM patients usually appear after $20 \mathrm{GW}$ [24]. Hence, we measured EAT thickness at 16 weeks +0 days to 19 weeks +6 days, a time point at which hyperglycemia is generally not present. This measurement was therefore taken 1 to 2 months prior to diagnosis, and would therefore be highly beneficial in that it could identify patients who have a risk of GDM and provide clinicians with sufficient time to develop appropriate treatment strategies.

Our analysis revealed that EAT thickness was significantly increased in the GDM group compared to the control group when measured between 16 weeks +0 days and 19 weeks +6 days. Furthermore, higher EAT thickness was significantly associated with adverse outcomes in GDM patients. We propose that there are two mechanisms that might be responsible for the increased EAT thickness in GDM patients. Firstly, the higher levels of retinol-binding protein 4 and lower levels of adiponectin secreted by adipose tissue, including EAT, prior to $16 \mathrm{GW}[25,26]$, could cause insulin resistance (IR), the main mechanisms underlying GDM [27]. Secondly, during the first-second trimester, EAT releases higher levels of pro-inflammatory adipokines (RBP4, hs-CRP, fatty acid-binding protein-4, leptin, and visfatin), and lower levels of anti-inflammatory adipokines (omentin-1 and adiponectin); these may participate in the chronic low-grade state of inflammation that has previously been confirmed to be associated with GDM [26, 28].

Pregnancy can be viewed as a cardiovascular stress test in that the development of certain complications has the potential to reveal a woman's susceptibility for future vascular or metabolic disease [29]. A previous study showed that GDM patients who had an increased EAT thickness during pregnancy were associated with subclinical atherosclerosis 6 years postpartum [21, 30]. The association between EAT and postpartum cardiovascular diseases therefore needs to be addressed further in future research. We aim to set up a new study, with a longer follow-up duration, to determine whether patients at a high-risk of GDM, as identified by EAT, are associated with T2DM and cardiovascular diseases. This type of study will allow us to implement preventive measures for this particular population.

\section{Limitations}

There are some limitations to our study that need to be considered. For example, all of our participants were Asian women. It is possible that race may be an important consideration when analyzing the relationship between EAT and the risk of disease [31]. Furthermore, we did not analyze data relating to inflammatory biomarkers; such data may be beneficial with regards to the efficacy of the EAT thickness model during the early second trimester.

\section{Conclusion}

Collectively, our findings indicate that echocardiographic EAT thickness is positively and significantly associated with GDM risk and adverse outcomes related to GDM. Echocardiographic EAT has the potential to be a predictor for GDM prior to actual clinical diagnosis.

\section{Abbreviations}

BMI: Body mass index; Cls: Confidence intervals; GDM: Gestational diabetes mellitus; GW: Gestational week; HDL-C: High-density lipoprotein cholesterol; IR: Insulin resistance; LDL-C: Low-density lipoprotein cholesterol; OR: Odds ratio; T2DM: Type 2 diabetes mellitus; VAT: Visceral adipose tissue.

\section{Acknowledgments \\ None.}

\section{Authors' contributions}

$J$ drafted the manuscript. GS participated in manuscript writing, data collection, and data analysis. TM participated in project development and manuscript writing. GZ participated in data collection and data analysis. All authors read and approved the manuscript.

\section{Funding}

This study was supported by the National Natural Science Foundation of China (Grant No. 81871173). The funder had no role in the design of the study, collection, analysis, and interpretation of data, or in writing the manuscript.

\section{Availability of data and materials \\ The datasets used and/or analyzed during the current study are available from the corresponding author on reasonable request.}

\section{Ethics approval and consent to participate}

This study was approved by the Medical Ethics Review Board of China Medical University (Shenyang, Liaoning, China). All participants provided written informed consent.

\section{Consent for publication}

Not applicable.

\section{Competing interests}

The authors declare that they have no competing interests.

\section{Author details}

'Department of Obstetrics, The First Affiliated Hospital of China Medical University, No. 155 Nanjing North Street, Heping District, Shenyang 110001, Liaoning Province, China. ${ }^{2}$ Department of Ultrasound, Shengjing Hospital of China Medical University, Shenyang, China.

Received: 11 February 2020 Accepted: 12 April 2020

Published online: 19 April 2020

\section{References}

1. Bevier WC, Jovanovic-Peterson L, Peterson CM. Pancreatic disorders of pregnancy. Diagnosis, management, and outcome of gestational diabetes. Endocrinol Metab Clin N Am. 1995;24(1):103-38.

2. Zhu Y, Zhang C. Prevalence of gestational diabetes and risk of progression to type 2 diabetes: a global perspective. Curr Diab Rep. 2016;16(1):7.

3. Mclntyre HD, Catalano P, Zhang C, Desoye G, Mathiesen ER, Damm P. Gestational diabetes mellitus. Nat Rev Dis Primers. 2019;5(1):47.

4. Kumru P, Arisoy R, Erdogdu E, Demirci O, Kavrut M, Ardic C, Aslaner N, Ozkoral A, Ertekin A. Prediction of gestational diabetes mellitus at first trimester in low-risk pregnancies. Taiwan J Obstet Gynecol. 2016;55(6):81520.

5. Correa PJ, Venegas P, Palmeiro Y, Albers D, Rice G, Roa J, Cortez J, Monckeberg M, Schepeler M, Osorio E, et al. First trimester prediction of gestational diabetes mellitus using plasma biomarkers: a case-control study. J Perinat Med. 2019;47(2):161-8.

6. Hamdy O, Porramatikul S, Al-Ozairi E. Metabolic obesity: the paradox between visceral and subcutaneous fat. Curr Diabetes Rev. 2006;2(4):367-73. 
7. Pierdomenico SD, Pierdomenico AM, Cuccurullo F, lacobellis G. Metaanalysis of the relation of echocardiographic epicardial adipose tissue thickness and the metabolic syndrome. Am J Cardiol. 2013;111(1):73-8.

8. Li Y, Liu B, Li Y, Jing $X$, Deng $S$, Yan $Y$, She Q. Epicardial fat tissue in patients with diabetes mellitus: a systematic review and meta-analysis. Cardiovasc Diabetol. 2019;18(1):3.

9. lacobellis G, Willens HJ, Barbaro G, Sharma AM. Threshold values of high-risk echocardiographic epicardial fat thickness. Obesity (Silver Spring). 2008;16(4): 887-92.

10. Liu J, Song G, Meng T, Zhao G, Guo S. Weight retention at six weeks postpartum and the risk of gestational diabetes mellitus in a second pregnancy. BMC Pregnancy Childbirth. 2019;19(1):272.

11. Henry OA, Beischer NA. Long-term implications of gestational diabetes for the mother. Baillieres Clin Obstet Gynaecol. 1991;5(2):461-83.

12. lacobellis $\mathrm{G}$, Willens HJ. Echocardiographic epicardial fat: a review of research and clinical applications. J Am Soc Echocardiogr. 2009;22(12):13119 quiz 1417-1318.

13. Weinert LS. International Association of Diabetes and Pregnancy Study Groups recommendations on the diagnosis and classification of hyperglycemia in pregnancy: comment to the International Association of Diabetes and Pregnancy Study Groups Consensus Panel. Diabetes Care. 2010;33(7):e97 author reply e98.

14. Williams AF. Hypoglycaemia of the newborn: a review. Bull World Health Organ. 1997;75(3):261-90.

15. Szmuilowicz ED, Josefson JL, Metzger BE. Gestational diabetes mellitus. Endocrinol Metab Clin N Am. 2019;48(3):479-93.

16. American Academy of Pediatrics Subcommittee on $\mathrm{H}$. Management of hyperbilirubinemia in the newborn infant 35 or more weeks of gestation. Pediatrics. 2004;114(1):297-316.

17. De Souza LR, Berger H, Retnakaran R, Maguire JL, Nathens AB, Connelly PW, Ray JG. First-trimester maternal abdominal adiposity predicts Dysglycemia and gestational diabetes mellitus in Midpregnancy. Diabetes Care. 2016; 39(1):61-4.

18. Saif Elnasr I, Ammar H. Ultrasound markers for prediction of gestational diabetes mellitus in early pregnancy in Egyptian women: observational study. J Matern Fetal Neonatal Med. 2020;1-7. https://doi.org/10.1080/ 14767058.2019.1678132. [Epub ahead of print].

19. D'Ambrosi F, Rossi G, Soldavini CM, Di Maso M, Carbone IF, Cetera GE, Colosi E, Ferrazzi E. Ultrasound assessment of maternal adipose tissue during 1st trimester screening for aneuploidies and risk of developing gestational diabetes. Acta Obstet Gynecol Scand. 2020. https://doi.org/10. 1111/aogs.13800. [Epub ahead of print].

20. Marchington JM, Pond CM. Site-specific properties of pericardial and epicardial adipose tissue: the effects of insulin and high-fat feeding on lipogenesis and the incorporation of fatty acids in vitro. Int J Obes. 1990;14(12):1013-22.

21. Caliskan M, Caklili OT, Caliskan Z, Duran C, Ciftci FC, Avci E, Gullu H, Kulaksizoglu M, Koca H, Muderrisoglu H. Does gestational diabetes history increase epicardial fat and carotid intima media thickness? Echocardiography. 2014;31(10):1182-7.

22. Nar G, Inci S, Aksan G, Unal OK, Nar R, Soylu K. The relationship between epicardial fat thickness and gestational diabetes mellitus. Diabetol Metab Syndr. 2014;6(1):120.

23. Yavuz A, Akkurt MO, Yalcin S, Karakoc G, Varol E, Sezik M. Second trimester fetal and maternal epicardial fat thickness in gestational diabetic pregnancies. Horm Metab Res. 2016;48(9):595-600.

24. Boriboonhirunsarn D, Sunsaneevithayakul P, Nuchangrid M. Incidence of gestational diabetes mellitus diagnosed before 20 weeks of gestation. J Med Assoc Thai. 2004;87(9):1017-21.

25. Ategbo JM, Grissa O, Yessoufou A, Hichami A, Dramane KL, Moutairou K Miled A, Grissa A, Jerbi M, Tabka Z, et al. Modulation of adipokines and cytokines in gestational diabetes and macrosomia. J Clin Endocrinol Metab. 2006;91(10):4137-43.

26. Lorenzo-Almoros A, Hang T, Peiro C, Soriano-Guillen L, Egido J, Tunon J, Lorenzo O. Predictive and diagnostic biomarkers for gestational diabetes and its associated metabolic and cardiovascular diseases. Cardiovasc Diabetol. 2019;18(1):140.

27. Catalano PM, Tyzbir ED, Roman NM, Amini SB, Sims EA. Longitudinal changes in insulin release and insulin resistance in nonobese pregnant women. Am J Obstet Gynecol. 1991;165(6 Pt 1):1667-72.

28. Baker AR, Silva NF, Quinn DW, Harte AL, Pagano D, Bonser RS, Kumar S, McTernan PG. Human epicardial adipose tissue expresses a pathogenic profile of adipocytokines in patients with cardiovascular disease. Cardiovasc Diabetol. 2006;5:1.

29. Williams D. Pregnancy: a stress test for life. Curr Opin Obstet Gynecol. 2003; 15(6):465-71.

30. Li JW, He SY, Liu P, Luo L, Zhao L, Xiao YB. Association of gestational diabetes mellitus (GDM) with subclinical atherosclerosis: a systemic review and meta-analysis. BMC Cardiovasc Disord. 2014;14:132.

31. Salami SS, Tucciarone M, Bess R, Kolluru A, Szpunar S, Rosman H, Cohen G. Race and epicardial fat: the impact of anthropometric measurements, percent body fat and sex. Ethn Dis. 2013;23(3):281-5.

\section{Publisher's Note}

Springer Nature remains neutral with regard to jurisdictional claims in published maps and institutional affiliations.
Ready to submit your research? Choose BMC and benefit from:

- fast, convenient online submission

- thorough peer review by experienced researchers in your field

- rapid publication on acceptance

- support for research data, including large and complex data types

- gold Open Access which fosters wider collaboration and increased citations

- maximum visibility for your research: over $100 \mathrm{M}$ website views per year

At BMC, research is always in progress.

Learn more biomedcentral.com/submissions 